\title{
A rare case of asymptomatic solitary cutaneous mastocytoma in a child
}

\author{
Sonam Jain ${ }^{1}$, Saumya Nanda ${ }^{2}$, Malvika Shastri ${ }^{1}$, Divya Sethi ${ }^{3}$ \\ From ${ }^{1}$ Senior Residents, Department of Pathology, ESI Hospital, Rohini, New Delhi, India, ${ }^{2}$ Final Year MBBS Student, Lady Hardinge Medical \\ College, New Delhi, India, ${ }^{3}$ Post Intern, Department of Pathology, ESI Hospital, Rohini, New Delhi, India
}

\begin{abstract}
Mastocytosis is a rare group of disorders occurring when mast cells diffusely infiltrate the skin or internal organs. It has two forms: Cutaneous and systemic mastocytosis. We present a case of a 12-year-old male child presenting with a reddish-brown cutaneous nodule on the anterior chest wall for 1 month. No other similar lesions were noted elsewhere. Routine hematological and radiological investigations did not reveal any abnormality. The lesion was excised, and a diagnosis of solitary cutaneous mastocytoma was made based on the clinical, histopathological, and immunohistochemical features. This case highlights the importance of diagnosing this rare tumor which can present as an asymptomatic cutaneous lesion in a young child.
\end{abstract}

Keywords: Asymptomatic mastocytosis, Cutaneous mastocytoma, Darier's sign, Solitary mastocytoma

$\mathrm{M}$ astocytosis is characterized by diffuse infiltration of mast cells in the skin or internal organs. It has two forms: Cutaneous and systemic mastocytosis. The former is usually seen in children and affects only skin. It may even be asymptomatic. It is further classified as generalized urticaria pigmentosa, solitary mastocytoma (SM), diffuse mastocytosis (DCM), and telangiectatic macularis eruptive perstans [1]. The cutaneous form is more common in children than in adults. Studies estimate its prevalence as roughly 1/500 children; however, definite figures are lacking [2]. Systemic mastocytosis mainly affects adults and can involve the bone marrow, lymph nodes, spleen, liver, and gastrointestinal tract mucosa [3]. The symptomatology varies depending on organ system involvement and local or systemic mediators released by these cells [4]. The cutaneous form in children is known to regress spontaneously by the age of puberty [2]. However, regular follow-up remains crucial in detecting progression to its systemic form. We present a case of solitary cutaneous mastocytoma presenting as chest wall nodule in a young male child.

\section{CASE REPORT}

A 12-year-old male presented with a single reddish-brown colored, pea-sized nodule on the anterior chest wall region for the past 1 month. It was progressively increasing in size for a week. No similar lesions were noted anywhere else on the body.

\section{Access this article online}

Received - 12 September 2021

Initial Review - 28 September 2021

Accepted - 27 October 2021

DOI: $10.32677 /$ ijcr.v7i11.3113
There were no associated complaints such as flushing, pruritus, vomiting, diarrhea, syncope, palpitation, and weight loss. Family history was insignificant.

His general physical examination was unremarkable; the vitals were within normal limits. Local examination revealed a single cutaneous nodule measuring $1.5 \times 1.5 \mathrm{~cm}$ on the anterior chest wall (Fig. 1). There was no wheal with flare on stroking the lesion (negative Darier's sign).

Routine investigations such as complete blood count (CBC) with differential count, renal function tests, liver function tests, random blood glucose, thyroid function tests, urine and plasma histamine metabolite levels, serum tryptase level, and urine routine examination were within normal limits. Chest X-ray and ultrasound of abdomen and pelvis did not reveal any abnormality. Hence, differential diagnoses comprising melanocytic nevi, xanthoma, xanthogranuloma, neurofibroma, and SM were considered.

The lesion was completely excised and sent for histopathologic examination. Grossly, the nodule was skin-covered, measuring $2 \times 2 \mathrm{~cm}$. The cut section was gray-white.

On microscopy, the stratified squamous epithelium was unremarkable. However, the underlying dermis showed a dense infiltrate of closely packed round to oval cells, having abundant eosinophilic granular cytoplasm and central to eccentrically placed nuclei with coarse chromatin (Fig. 2). Giemsa stain highlighted the metachromatic cytoplasmic granules of these cells, hinting at these being mast cells (Fig. 3). Further, immunostain for CD117 was strongly positive in these cells, confirming them as mast cells (Fig. 4).

Correspondence to: Saumya Nanda, G 506, Somvihar, New Delhi - 110022 , India. E-mail: saumyananda66@googlemail.com

(C) 2021 Creative Commons Attribution-NonCommercial 4.0 International License (CC BY-NC-ND 4.0). 


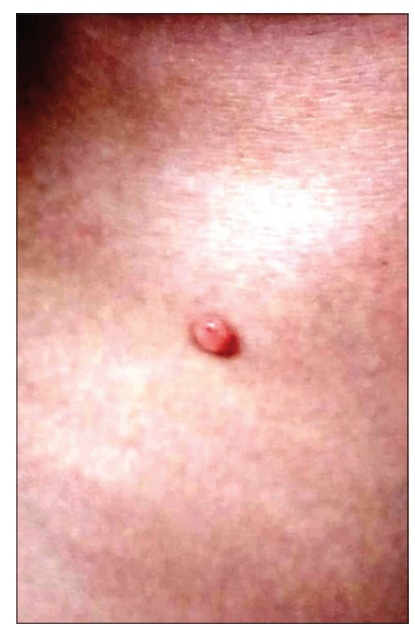

Figure 1: Solitary reddish-brown cutaneous nodule over the anterior chest wall

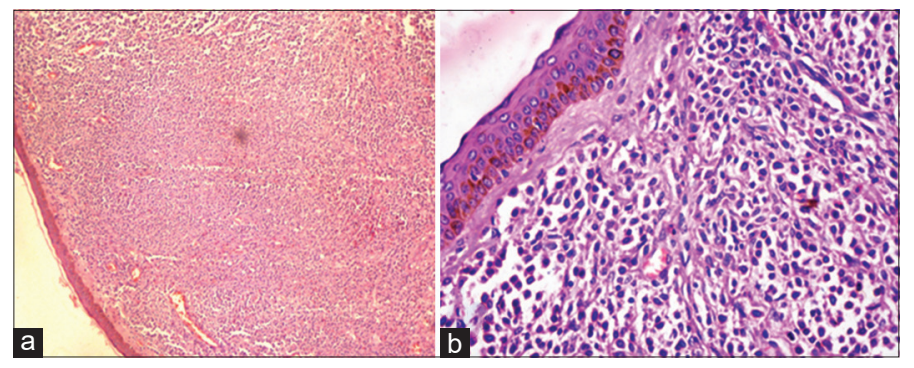

Figure 2: Diffuse dermal infiltration of round to oval cells having eosinophilic granular cytoplasm, central to eccentrically placed nuclei with coarse chromatin (a) (hematoxylin and eosin [H and E], $\times 10)$ and $(b)(H$ and $E, \times 40)$

Thus, a final diagnosis of asymptomatic solitary cutaneous mastocytoma was made. Up till 1 year of follow-up, the patient had no systemic symptoms or development of any fresh lesions on the skin.

\section{DISCUSSION}

Mastocytosis is a rare disorder with an annual incidence rate of 5-10 new cases/million [5]. It affects all races and has no sex predilection. The first peak is seen during infancy and early childhood while the second peak is noted during middle age $[6,7]$. Urticaria pigmentosa is the most common type of mastocytosis, comprising $58-90 \%$ of all cutaneous mastocytosis. DCM is the rarest subtype [6]. The cutaneous form of SM was first described by Nettleship in 1889 and accounts for $10-15 \%$ of all cutaneous mastocytosis [8].

Mast cells are connective tissue cells originating from pluripotent progenitor cells in the bone marrow and express CD34, CD117 (c-kit), and CD13 [5]. These cells traverse through blood vessels and invade the tissue. Their role is influenced by the stem cell factor, c-kit. The kit ligand binds to the kit protein present on the surface of the mast cell and plays a crucial role in the growth and development of the cell [5]. Mutations in the c-kit gene at codon 816 (c-kit D816V) results mostly into cutaneous mastocytosis [9]. Another proposed hypothesis is the dysregulation of mast cell apoptosis resulting in the upregulation

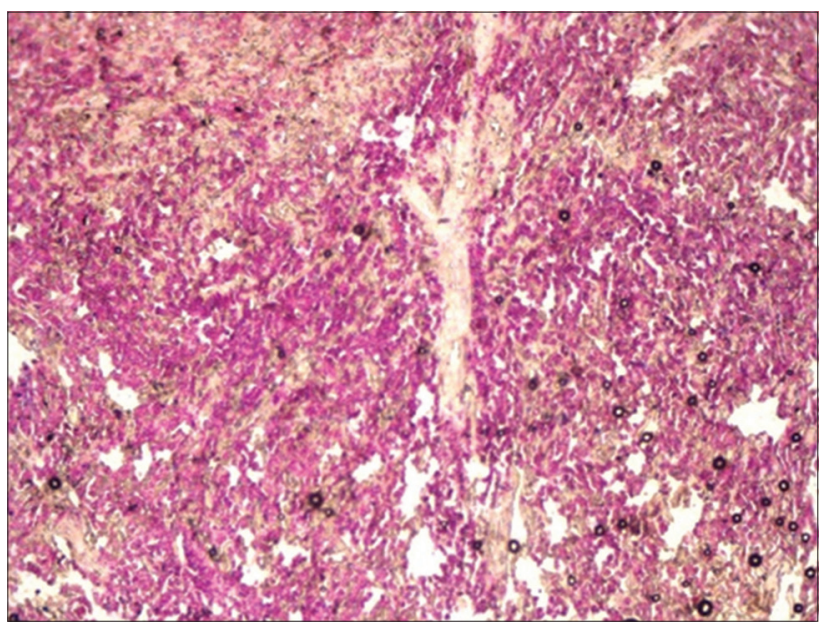

Figure 3: Giemsa stain showing metachromatic cytoplasmic granules of mast cells

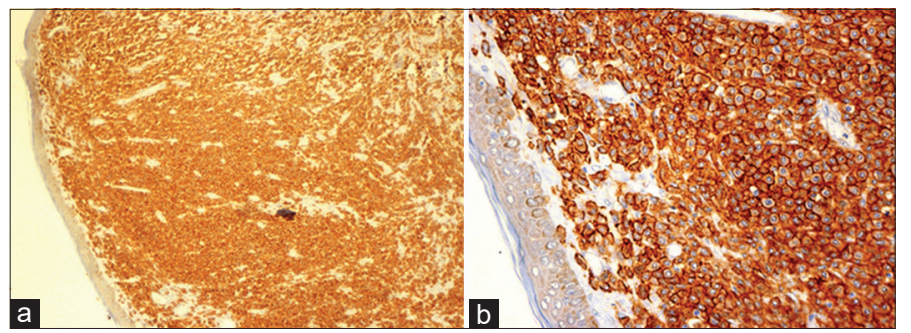

Figure 4: An immunohistochemical stain directed against CD117 highlights the mast cell infiltrate (a) (hematoxylin and eosin $[\mathrm{H}$ and $\mathrm{E}], \times 10)$ and $(\mathrm{b})(\mathrm{H}$ and $\mathrm{E}, \times 40)$

of antiapoptotic protein B-cell lymphoma (Bcl) 2 and Bcl-X resulting into systemic mastocytosis [10].

SM usually presents during infancy and only $10 \%$ appear after 2 years of age [8]. Its diagnosis is mainly clinical. Clinical details related to the lesions such as its onset, duration, progression, and triggering factors are important. Positive family history is also of significant value. These lesions are solitary, reddish-brown papules, or nodules commonly seen on the trunk, extremities, head, and neck [11]. The signs and symptoms are secondary to the release of mediators such as histamine, heparin, tryptase, leukotrienes, cytokines, and chemokines. These are triggered by physical stimuli (heat, cold, friction, and pressure), emotional factors, non-steroidal anti-inflammatory drugs intake, opioids, and radiocontrast dyes [8]. The symptoms include pruritus or blistering when localized and flushing, vomiting, diarrhea, syncope, palpitation, and weight loss when generalized. The typical clinical appearance of lesions in combination with positive Darier's sign is the characteristic feature of the disease. However, in only $50 \%$ of cases, Darier's sign is positive [8]. Rarely, the patients are asymptomatic. In the present case also, there were no other symptoms except for a solitary cutaneous nodule on the anterior chest wall.

The diagnosis is confirmed by histopathological examination which shows diffuse dermal infiltration by mast cells. Toluidine blue, Giemsa stain, and Leder's stain are special stains that help to identify the metachromatic cytoplasmic granules as seen in the present case. The confirmation is supported by positive 
c-kit/CD-117 on immunohistochemistry [9]. In children, other laboratory investigations are needed only when there is extracutaneous involvement. The initial investigations include $\mathrm{CBC}$ with differential count, urine and plasma histamine metabolite levels, and serum tryptase level. In $80 \%$ cases of systemic mastocytoma, serum tryptase level is more than $20 \mathrm{ng} / \mathrm{ml}$ (normal level $<11.5 \mathrm{ng} / \mathrm{ml}$ ) [5]. In the present case, serum tryptase level was normal. $\mathrm{N}$-methyl histamine and $\mathrm{N}$-methyl imidazylacetic acid are the histamine metabolites detected in the urine [5]. Their raised levels are indicative of the increased number of mast cells in the skin. A bone marrow examination and whole-body imaging can be further performed to confirm systemic involvement. Chest radiography and abdominal ultrasonography were unremarkable in the present case, thus ruling out internal organ involvement.

The management is aimed at preventing mediator release using antihistaminics, cromolyn sodium, aspirin, and avoidance of triggering factors. Other treatment modalities include topical and intralesional corticosteroids, psoralens, ultraviolet-A, application of calcineurin inhibitors, and targeted laser therapy [12]. In unresponsive cases, surgical excision can be the choice of treatment. However, in solitary or few lesions, surgical excision can be the first-line therapy, as was done in the present case.

A diagnosis of cutaneous mastocytosis relies heavily on clinical presentation. In pediatric patients, the clinical presentation differs from that in adults. There is also a difference in the behavior among the two age groups. Awareness regarding age and clinical presentation can allow for quicker identification and consideration of this entity as a possible differential diagnosis in children. This will have definite implications on the management of this condition which includes both medical as well as surgical modalities of treatment.

\section{CONCLUSION}

The diagnosis of SM is difficult, especially in asymptomatic cases. Accurate diagnosis is achieved using a triad of clinical, radiological, and histopathological examination along with immunohistochemical confirmation.

\section{REFERENCES}

1. Poulton JK, Kauffman CL, Lutz LL, Sina B. Solitary mastocytoma arising at a hepatitis B vaccination site. Cutis 1999;63:37-40.

2. Kiszewski AE, Durán-Mckinster C, Orozco-Covarrubias L, GutiérrezCastrellón P, Ruiz-Maldonado R. Cutaneous mastocytosis in children: A clinical analysis of 71 cases. J Eur Acad Dermatol Venereol 2004;18:285-90.

3. Horny HP, Akin C, Metcalfe DD, Escribano L, Bennett JM, Valent P, et al. Mastocytosis (mast cell disease). In: Swerdlow SH, Campo E, Harris NL, Jaffe ES, Pileri SA, editors. WHO Classification of Tumours. Pathology and Genetics. Tumours of Haematopoietic and Lymphoid Tissues. Lyon, France: IARC Press; 2008. p. 54-63.

4. Andersen CL, Kristensen TK, Severinsen MT, Moller MB, Vestergaard H, Bergmann OJ, et al. Systemic mastocytosis--a systematic review. Dan Med J 2012;59:A4397.

5. Srinivas SM, Dhar S, Parikh D. Mastocytosis in children. Indian J Paediatr Dermatol 2015;16:57-63.

6. Castells M, Metcalfe DD, Escribano L. Diagnosis and treatment of cutaneous mastocytosis in children: Practical recommendations. Am J Clin Dermatol 2011;12:259-70.

7. Nagargoje M, Salunke A. Histopathological study of a rare cutaneous lesionsolitary mastocytoma. Int J Sci Res 2016;5:475-6.

8. Gopal D, Puri P, Singh A, Ramesh V. Asymptomatic solitary cutaneous mastocytoma: A rare presentation. Indian J Dermatol 2014;59:634.

9. Yanagihori H, Oyama N, Nakamura K, Kaneko F. C-kit mutations in patients with childhood-onset mastocytosis and genotype-phenotype correlation. J Mol Diagn 2005;7:252-7.

10. Hartman K, Zirbes TK, Hasan S, Gilfillan AM, Henz BM, Metcalfe DD. Expression of the antiapoptotic protein Bcl-X in human mast cells and mastocytosis. J Allergy Clin Immunol 2000;105:S66.

11. Valent P, Akin C, Escribano L, Födinger M, Hartmann K, Brockow K, et al. Standards and standardization in mastocytosis: Consensus statements on diagnostics, treatment recommendations and response criteria. Eur J Clin Invest 2007;37:435-53.

12. Heide R, Beishuizen A, De Groot H, Den Hollander JC, Van Doormaal JJ, De Monchy JG, et al. Mastocytosis in children: A protocol for management. Pediatr Dermatol 2008;25:493-500.

Funding: None; Conflicts of interest: None Stated.

How to cite this article: Jain S, Nanda S, Shastri M, Sethi D. A rare case of asymptomatic solitary cutaneous mastocytoma in a child. Indian J Case Reports. 2021;7(11):477-479. 